\title{
Retention of a position discrimination after regeneration in planarians
}

\author{
W. C. CORNING ${ }^{1}$ \\ MICHIGAN STATE UNIVERSITY
}

When planarians are trained in a right-left discrimination and then sectioned, both the anterior and posterior portions demonstrate retention of the discrimination after regeneration. In subsequent retraining trials these $S$ s also require fewer trials to reach criterion than the original Ss. Control groups indicate that the retention levels are comparable to those of trained uncut animals and that regeneration by itself does not facilitate learning

Previous research has indicated that if planarians which have been classically conditioned in a lightshock paradigm are transected and allowed to regenerate, the anterior and posterior regenerates exhibit savings of the conditioned response during subsequent retraining trials (Corning \& John, 1961; McConnell, Jacobson \& Kimble, 1959). Others have contended that the process of regeneration effects a heightened sensitivity to light, and that the savings could be due to factors other than retention of the conditioned habit in the regenerated animals (Brown, 1964; Brown \& Beck, 1964; Van Deventner \& Ratner, 1964).

The evidence obtained in the present study demonstrates that a position discrimination is retained after regeneration. The use of a discriminated position response avoids any possibility of photosensitization and lends further support to studies which suggest that learning involves systems throughout the planarian, and that the information stored by these systems survives the regenerative processes.

Method

The Ss were 68 Dugesia dorotocephala randomly selected from a general population of over 500 animals. Each of the Ss was kept in a separate bowl containing $225 \mathrm{ml}$ of pond water. They were fed beef liver twice weekly and had their water changed after each feeding.

Details of the mazes and procedures have been described previously (Corning, 1964). For the purpose of summary, the mazes were of a " $T$ " design and constructed of clear Plexiglas. During the trial sessions, the mazes were positioned over the Ss' bowls so that only the ends of the sloping arms were below the water level. The alleys were kept moist throughout the training period.

Each $\mathrm{S}$ received five trials per day with an intertrial interval of 5 to $12 \mathrm{~min}$. The first 10 trials for each of the Ss were preference testing trials; the Ss were permitted to use either arm to escape the maze and return to their home bowl. Thereafter, they were trained to enter the least preferred arm. When the incorrect arm was chosen, the animal was given a gentle poke at its anterior end with a camel's hair brush, a procedure which caused a withdrawal into the stem of the maze. A correct response was recorded for a trial if the animal entered the correct arm and did not receive a poke for a wrong choice.

Four groups of Ss were used. To determine whether the discrimination survived regeneration, Group I Ss $(N=10)$ were trained to a criterion of 9 out of 10 correct responses, sectioned transversely just anterior to the pharynx, and allowed to regenerate 18 to 26 days. The anterior and posterior regenerates were then given 10 additional preference testing trials and retrained to criterion. Group II provided data on the response levels of untrained Ss in the maze. Thirty-four animals were presented maze trials but were allowed to select either arm to escape the maze. Group III was used to determine if the process of regeneration could facilitate learning; 18 naive planarians were sectioned, allowed to regenerate, and then trained. A measure of the degree of retention that could be expected in trained uncut planarians was provided by Group IV; 6 Ss were trained to criterion, left for 20 to 25 days and then given preference tests. For all groups, the testing sessions were conducted "blind"; the Ss were coded so that the experimenter did not know to which group they belonged.

\section{Results and Discussion}

As can be seen from the data represented in Fig. 1, there is a marked reversal of the original position preference in the regenerated portions of Group I and also a higher correct response level during retraining. For the first 10 trials of preference testing, the original

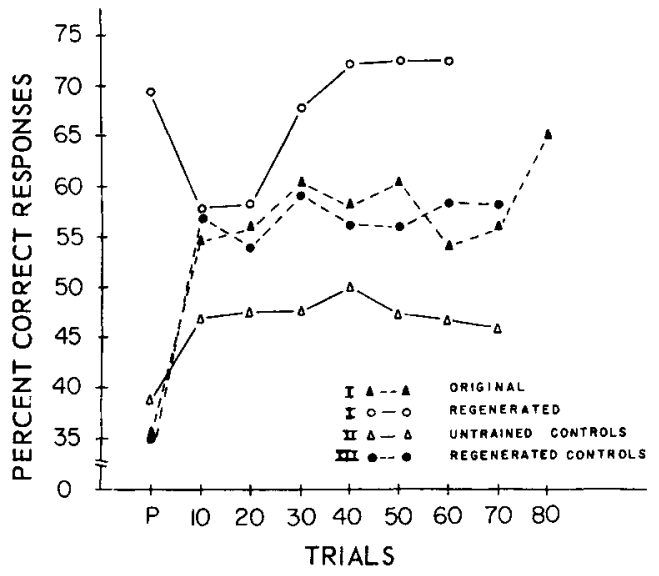

Fig. 1. Average percent correct response performance of planarians in a single unit maze. "P"' signifies preference tests. 
Ss of Group I chose the arm to which they were later trained an average of $35.3 \%$. After training to criterion, sectioning and regeneration, the anterior and posterior regenerates displayed average correct response levels of $68.6 \%$ and $69.8 \%$ (since the means of the anterior and posterior groups were nearly the same during preference testing and retraining, they have been combined in Fig. 1). Statistical analyses ( $t$-tests) indicate that the scores of the regenerated Ss during the post-regeneration preference testing differed significantly from the preferences exhibited by the original Ss (tails: $p<.005$; heads: $p<.025)$. Examination of the number of trials required to achieve criterion also demonstrates savings in the regenerated Ss; while the original Ss took an average of 39.8 trials to reach criterion, their regenerated anterior and posterior sections took 21.8 and 20.7 trials respectively to reach the same criterion $(p<.025$ for each group when compared with the original Ss).

The response levels observed in the Ss of Group II show that when the animals were allowed to select either arm to escape the maze, their performance is random. None of these Ss ever selected the non-preferred arm 9 out of 10 times. The data obtained from Group III demonstrates that the process of regeneration cannot account for the improved performance in the regenerates of Group I. When the naive regenerated animals of Group III were trained, their acquisition scores were not significantly different from those of the original Ss in Group I. The anterior regenerates required 42.4 trials and the posterior portions 41.3 trials to reach criterion. The Ss of Group IV displayed a correct response level of $60.1 \%$ during their second performance test which was significantly higher $(p<.05)$ than their initial preference of $34.9 \%$ (these data not shown in Fig. 1). These scores were not significantly different from the levels observed during preference testing in the regenerated portions of Group I animals.

From these results, it is clear that the residual traces of training are pronounced in the regenerated offspring of previously trained planarians. Furthermore, the performance of the anterior and posterior derivatives are equal, confirming the original findings by McConnell et al (1959) for a classically conditioned response, and the data reported by Ernhart \& Sherrick (1959) for a water-filled two-unit maze ${ }^{2}$

\section{References}

Brown, H. M. Photoreversal of the light-response decrement in planaria due to ultraviolet light. Amer. Psychologist, 1964, 19, 484. (Abstract)

Brown, H. M., \& Beck, E. C. Does learning in planaria survive regeneration? Fed. Proc., 1964, 23, No. 2.

Corning, W. C. Evidence of right-left discrimination in planarians. J. Psychol., 1964, 58, 131-139.

Coming, W. C., \& John, E. R. Effect of ribonuclease on retention of conditioned response in regenerated planarians. Science, $1961,134,1363-1364$.

Ernhart, E. N., \& Sherrick, C. Retention of a maze habit following regeneration in planaria (D. maculata). Paper presented at Midwestern Psychological Association, May, 1959.

McConnell, J. V., Jacobson, A. L., \& Kimble, D. P. The effects of regeneration upon retention of a conditioned response in the planarian. J. comp. physiol. Psychol., 1959, 52, 1-5.

VanDeventner, J. M., \& Ratner, S. Variables affecting the frequency of response of planaria to light. J. comp. physiol. Psychol., i964, 57, 407-411.

\section{Notes}

1. Present address: Department of Psychology, Fordham University, Bronx, N. Y.

2. The present paper is a portion of the research carried out under Grant NSG 475, National Aeronautics and Space Administration. The author is indebted to S. Feinstein, D. A. Feinstein, and C. Rouse for their assistance in the research.

\section{ERRATUM}

Moyer, K. E。, \& Chapman, J. A. Effect of continuous vS. discontinuous shock on shuttle box avoidance in the rat. Psychon.Sci., 1966, 4(5), 197-198.-In this experiment the description of procedure was incorrect. The Ss were described as running from a dark grid to a lighted one in order to escape or avoid shock. The reverse was, in fact, true. The Ss ran from the lighted grid to the dark grid. 